\title{
O PROGRAMA DE INCLUSÃO DIGITAL DO GOVERNO BRASILEIRO: ANÁLISE SOB A PERSPECTIVA DA INTERSEÇÃO ENTRE CIÊNCIA DA INFORMAÇÃO E INTERAÇÃO HUMANO COMPUTADOR
}

\author{
Calixto Silva Neto \\ José Oscar Fontanini de Carvalho
}

\section{Resumo:}

Apresenta uma análise do Programa de Inclusão Digital do Governo Brasileiro sob uma perspectiva resultante da intersecção entre as áreas da Ciência da Informação e da Interação Humano-Computador. Desenvolve os principais conceitos dos itens em questão. Discute a Interação Humano-Computador como componente do processo de disseminação e recuperação da informação por meio de computadores e promove uma aproximação entre a Área e a Ciência da Informação. Pesquisa, por meio de levantamento de dados e questionários aplicados em escolas de Ensino Fundamental, alguns dos resultados da aplicação do Programa de Inclusão Digital do Governo Brasileiro, visando subsidiar a análise desenvolvida.

\section{Palavras-Chave:}

Disseminação da informação; Interação humano-computador; Inclusão digital; Sociedade da informação; Recuperação de informação; Software livre

THE BRAZILIAN GOVERNMENT PROGRAM OF DIGITAL
INCLUSION: ANALYSIS ON THE PERSPECTIVE OF THE
INTERSECTION BETWEEN INFORMATION SCIENCE AND HUMAN-
COMPUTER INTERACTION

\begin{abstract}
:
It presents an analysis of the Brazilian Government Program of Digital Inclusion under the perspective of the Interaction between Information Science and Human-Computer Interaction and develops the main concepts of the items in question. It also discusses Human-Computer Interaction as a part of the process of dissemination and retrieval of information by means of computers and promotes an approach between the Area and the Information Science. The Research is supported by the use of questionnaire data-collecting applied in elementary schools and by some results of the Brazilian Government Program of Digital Inclusion, aiming at subsidize the developed analysis.
\end{abstract}

\section{Keywords:}

Information science; Information dissemination; Human-computer interaction; Digital inclusion; Information society; Information retrieval; Open software 


\section{1 - INTRODUÇÃO}

A inclusão digital é tema que desperta a preocupação e interesse tanto do governo brasileiro quanto de ONGs (Organizações Não-Governamentais), empresas, escolas e igrejas.

A inclusão digital se dá a partir do momento em que as pessoas que não tinham acesso aos meios digitais, para a recuperação da informação, conseguem tê-lo, usando máquinas (normalmente computadores), “softwares” e redes (normalmente a Internet). Quando há acesso, e por conseqüência recuperação de informação, fica possível também a produção e disseminação de informações. De acordo com o governo brasileiro, a inclusão digital favorece e auxilia a inclusão social.

Não basta ter políticas de financiamento para aquisição de computadores e uso de “softwares” a custo baixo ou zero, mas também há necessidade de investimentos em capacitação para que o usuário, objeto da inclusão digital, tenha condição de manusear os dispositivos digitais. Capacitação não é um produto, como computador ou "software”, mas sim um bem intangível que necessita de altos investimentos financeiros e tempo para aprendizado e assimilação, conforme escreve Carvalho (2003, p.78):

\footnotetext{
O espaço, que marca a separação da comunicação entre o ser humano e a máquina tem a sua maior parte percorrida pelo homem, devido a sua maior capacidade para a adaptação. Ele conquista este espaço por meio da capacitação, ficando com a maior parte do peso da interação entre o ser humano e a máquina sobre seus ombros. Uma alternativa é fazer com que a máquina percorra o espaço em direção ao ser humano.
}

Esse espaço que a máquina poderia percorrer refere-se a um projeto de interface mais intuitivo ao ser humano, que torne a máquina mais próxima do modelo mental do sujeito, ou pelo menos mais próxima de modelos mentais já existentes e aprendidos. Uma área recente da Computação é a Interação Humano-Computador, de característica multidisciplinar, cujo objetivo é tornar as máquinas sofisticadas mais acessíveis, no quesito interação com os usuários.

No mundo globalizado e interconectado do século XXI, cada vez mais, há necessidade de habilidades para realizar pesquisas por meio de equipamentos eletrônicos, em grandes bases de dados espalhadas pelo mundo, nas quais a Internet desempenha um papel fundamental e importante. Atualmente há grande demanda e necessidade de informação e a inclusão digital se faz necessária para possibilitar ao cidadão sua inclusão social, pois 
praticamente qualquer área de trabalho se utiliza de computadores e "softwares”. Assim, para o cidadão ingressar no mercado de trabalho, há necessidade de conhecimentos em informática e uso da Internet.

O governo brasileiro apresenta várias soluções e programas para promover a inclusão digital, todos pautados na necessidade de disponibilizar computadores, seja nas escolas públicas, ou por meio de financiamentos e distribuição dos “softwares” necessários. Todos os programas estão pautados nas diretrizes da 'Sociedade da Informação no Brasil', coordenada pelo Ministério da Ciência e Tecnologia - MCT.

A grande preocupação do governo é com a diminuição dos preços dos computadores e o uso dos “softwares” livres (sem custo ou mais acessíveis) para promover a inclusão digital, o que parece ser uma equação muito simples. Além dos problemas relativos ao computador e "software", existem vários outros problemas que promovem a exclusão digital, como por exemplo:

sociais; políticos; econômicos; educacionais; de deficiências físicas ou cognitivas; entre outros. Além destes, um fator importante, porém menos discutido, na inclusão das pessoas no mundo digital é a facilidade, ou dificuldade, encontrada por elas para a operação das máquinas digitais (Carvalho, 2003, p.76).

Entre os vários objetivos da Ciência da Informação, também o são a disseminação e recuperação da informação, que coincide com os objetivos da Interação HumanoComputador, pois por meio da melhor interatividade, busca-se promover a recuperação e disseminação da informação de uma forma mais agradável, fácil e intuitiva.

No entanto não encontramos programas do governo preocupados com a capacitação do cidadão, em pesquisar e promover a interatividade ou projetos de interfaces. Tendo em vista o cenário apresentado, nascem algumas dúvidas e, entre elas, destacamos:

- A alternativa em usar “softwares” livres, cuja interface é desenvolvida para quem já está integrado no mundo digital, resolverá o problema da inclusão digital?

- A falta de um programa de capacitação ou do desenvolvimento de interfaces que promovam a Interação Humano-Computador prejudica a inclusão digital?

Para responder a essas questões, elaboramos um levantamento bibliográfico e realizamos uma pesquisa qualitativa junto a entidades que promovem a Inclusão Digital, com a 
finalidade de obter informações para verificar se a interação do ser humano com a máquina e a falta de capacitação prejudicam os objetivos dos programas governamentais sobre a Inclusão Digital.

Antes, porém, de apresentarmos os resultados da pesquisa faz-se necessária uma breve discussão de aspectos teóricos envolvidos no assunto.

\title{
2 - INFORMAÇÃO
}

A palavra informação pode ter diversos significados, com sentido ambíguo, dependendo do contexto em que está sendo empregada. Segundo Le Coadic (1996, p.5):

\begin{abstract}
A informação é um conhecimento inscrito (gravado) sob a forma escrita (impressa ou numérica), oral ou audiovisual.

A informação comporta um elemento de sentido. É um significado transmitido a um ser consciente por meio de uma mensagem inscrita em um suporte espacial-temporal: impresso, sinal elétrico, onda sonora etc. Essa inscrição é feita graças a um sistema de signos (a linguagem), signo este que é um elemento da linguagem que associa um significante a um significado: signo alfabético, palavra, sinal de pontuação.... o objetivo da informação permanece sendo a apreensão de sentidos ou seres em sua significação, ou seja, continua sendo o conhecimento.
\end{abstract}

Pela definição de Le Coadic, entendemos que a informação tem que ser registrada, gravada, inscrita, de alguma maneira, que tenha um caráter permanente, utilizando algum suporte, como papel, fita cassete, filme, audiovisual, disquete, CD-ROM e outros afins. O objetivo da informação é transmitir um significado, por meio de uma linguagem, para gerar conhecimento (um saber - ato de conhecer, formar idéia de algo), então, é um conjunto de fatos ou dados organizados de maneira que tenham um valor adicional (conhecimento). Assim, a informação na concepção aqui adotada, não existirá sem algum tipo de suporte e, como interage em um ambiente sistêmico (linguagem, contexto, saberes anteriores), pode apresentar diversidade de interpretação.

A explosão da informação, segundo Le Coadic (1996, p.7) ocorre após o surgimento da escrita, quando a comunicação passa de oral para escrita, com a possibilidade, inclusive, de armazená-la e, com baixo custo energético, multiplicá-la. A informática, fruto da evolução da eletrônica, permitiu aumentar a velocidade da multiplicação da informação, 
com seus computadores trabalhando em nanosegundos ${ }^{1}$ encurtou o tempo de execução de disseminação e recuperação da informação.

A informação é utilizada para mudar o estado de conhecimento de determinado assunto em determinado momento. Conhecer significa o sujeito utilizar sua competência cognitiva para interpretar e assimilar uma informação e, conforme relata Barreto (2002, p.49) informação, em nosso entender, se qualifica como um instrumento modificador da consciência do indivíduo e de seu grupo social, pois sintoniza o homem com a memória de seu passado e com as perspectivas de seu futuro.

Para a informação mudar o estado de conhecimento do sujeito, portanto da sociedade, é necessário que ela passe do estado privado, em sua produção, para o estado público, através da comunicação. Le Coadic (1996, p. 10-13) descreve esse processo social como um “ciclo de informação” composto de três partes: Construção, Comunicação e Uso. A comunicação é, portanto, o processo intermediário que permite a troca de informações entre as pessoas, ou seja, a informação é um produto e a comunicação um ato ou mecanismo que permite o uso da informação.

\section{3 - Inclusão Digital e as Políticas do Governo Brasileiro}

Atualmente, as informações estão sendo, cada vez mais, armazenadas em meios digitais, em função da facilidade em se armazená-las e recuperá-las e, também, pelos custos, tanto de mídias quanto de canais de comunicação e computadores que, a cada dia, reduzem mais seus preços. A Internet já está presente no cotidiano do ser humano tanto em residências quanto em escritórios, supermercados, comércio, escolas de todos os níveis, restaurantes, cafeterias e no lazer e o acesso mais comum, tanto para o armazenamento como para a recuperação da informação em meios digitais, ocorre por meio do computador, equipamento ao qual nem todos ainda têm acesso.

A expressão “excluídos da sociedade da informação” ficou reduzida para “exclusão digital”, com sua contrapartida “inclusão digital” e conforme a Sociedade da Informação, o Livro Verde apresenta:

\footnotetext{
${ }^{1}$ A medida de velocidade dos computadores é em Hertz (ciclos por segundo) e atualmente um computador médio trabalha na faixa de $3 \mathrm{Ghz}$ (três GigaHerts $=3.000 .000 .000$ de Hertz), o que resulta em um ciclo a cada $1 /\left(3 * 10^{9)}\right.$ segundos, ou nanosegundos.
} 
As tecnologias de informação e comunicação ainda não chegam à maior parte da população do planeta, em que pese o ritmo veloz de sua disseminação. Enquanto o mundo economicamente mais desenvolvido encontra-se envolto em um complexo de redes digitais de alta capacidade, utilizando intensamente serviços de última geração, uma parcela considerável da população dos demais países não tem acesso sequer à telefonia básica. O maior acesso à informação poderá conduzir as sociedades e relações sociais mais democráticas, mas também poderá gerar uma nova lógica de exclusão, acentuando as desigualdades e exclusões já existentes, tanto entre sociedades, como, no interior de cada uma, entre setores e regiões de maior e menor renda. No novo paradigma, a universalização dos serviços de informação e comunicação é condição necessária, ainda que não suficiente, para a inserção dos indivíduos como cidadãos. No Brasil, o crescimento recente das telecomunicações tem democratizado o uso do telefone. O acesso à rede Internet, contudo, ainda é restrito a poucos. Urge, portanto, buscar meios e medidas para garantir a todos os cidadãos o acesso eqüitativo à informação e aos benefícios que podem advir da inserção do País na sociedade da informação (Takahashi, 2000, p.7).

Um dos propósitos da Ciência da Informação é a disseminação da informação e conforme Le Coadic (1996, p. 33) outro propósito dessa função (comunicação da informação), bem menos praticado, é assegurar a difusão e a promoção da ciência junto a públicos de nãoespecialistas (inserir a ciência na cultura) e junto aos governos. A falta de acesso por parte de uma fatia da população aos meios tecnológicos, para a recuperação da informação, contribui para o aprofundamento da exclusão da Sociedade da Informação ou mais resumidamente, exclusão digital.

De acordo com um levantamento do Instituto Brasileiro de Geografia e Estatística (IBGE), na tabela de "Domicílios particulares permanentes urbanos, total e proporção dos domicílios por acesso a alguns serviços e posse de alguns bens duráveis, segundo as Grandes Regiões, Unidades da Federação e Regiões Metropolitanas - 2004”, o Brasil apresentava o seguinte quadro:

Tabela 1 - Tabela IBGE sobre Computadores e Internet

\begin{tabular}{|c|c|c|c|c|c|c|c|}
\hline \multicolumn{3}{|c|}{ Por acesso a alguns serviços (\%) } & \multicolumn{5}{c|}{ Por posse de bens duráveis (\%) } \\
\hline $\begin{array}{c}\text { Iluminação } \\
\text { elétrica }\end{array}$ & Telefone fixo & Internet & $\begin{array}{c}\text { Compu- } \\
\text { tador }\end{array}$ & $\begin{array}{c}\text { Gela- } \\
\text { deira }\end{array}$ & Freezer & $\begin{array}{c}\text { TV em } \\
\text { cores }\end{array}$ & $\begin{array}{c}\text { Máquina de } \\
\text { lavar }\end{array}$ \\
\hline $\mathbf{9 9 , 6}$ & 56,1 & 14,3 & 18,9 & 92,1 & 17,1 & $\mathbf{9 1 , 5}$ & 38,8 \\
\hline
\end{tabular}

Pela Tabela 1, notamos a presença de quase 100\% de fornecimento de energia elétrica nos domicílios urbanos e apenas 14,3\% de acesso à Internet. Com relação ao computador, o mesmo está presente somente em 18,9\% dos lares, enquanto a televisão aparece em 
91,5\%. Ainda, conforme o IBGE, a projeção de habitantes para 2004 foi de 182.060.108, então, 14,3\% resulta em 26.034.595 de habitantes com acesso à Internet.

No site do Ministério da Ciência e Tecnologia, encontramos a seguinte afirmação:

\begin{abstract}
A inclusão digital está estreitamente vinculada à problemática da inclusão social dos menos favorecidos. Isto porque o governo, por intermédio do MCT, está preocupado com a real necessidade em disponibilizar os meios e instrumentos que efetivamente criem as condições necessárias e suficientes para a geração de emprego e renda, objeto último dos esforços governamentais nos programas de inclusão social. O programa de inclusão digital, portanto, é um instrumento da promoção da inclusão social.

O programa de inclusão digital do Ministério da Ciência e Tecnologia pode ser resumido em: oferta de instrumentos, meios e facilidades, para os menos favorecidos, facilitando o acesso às oportunidades de emprego, geração de renda ou melhoria da renda através da melhor qualificação profissional e com isto transformar cidadãos brasileiros, hoje à margem, em participantes ativos do processo de desenvolvimento econômico e social. (http://www.mct.gov.br/index.php/content/view/9751.html).
\end{abstract}

Para o Programa da Sociedade da Informação do Ministério da Ciência e Tecnologia, a inclusão Digital e, por conseguinte, a inclusão social se dará por meio da oferta de instrumentos (computadores e "softwares”), meios (acesso à Internet e a redes) e facilidades (capacitação, treinamento, interação) para a parcela da população menos favorecida, que ainda não tem acesso aos instrumentos, meios e facilidades.

A exclusão digital é provocada por vários fatores, sendo, porém um dos mais importantes, a dificuldade de uma parte desse contingente de pessoas, em manusear e operacionalizar as máquinas digitais, aqui incluído o "software”. No Livro Verde da Sociedade da Informação no Brasil lê-se: Outro fator de dificuldade para o usuário inexperiente é o desenho das telas de apresentação e a estruturação das páginas, muitas vezes, pressupondo certa familiaridade com ambientes computacionais mais sofisticados (Takahashi, 2000, p.7).

Assim, uma das preocupações, tanto da Sociedade da Informação quanto da Ciência da Informação, é com a interação entre a pessoa (usuário) e a máquina, pois muitas pessoas, mesmo as mais bem preparadas culturalmente, têm dificuldades de interação com determinadas máquinas digitais, o que também é um fator gerador de exclusão digital. Atualmente, como já foi dito anteriormente, esse problema tem uma área de estudo específica que é a Interação Humano-Computador - IHC.

(c) Revista Digital de Biblioteconomia e Ciência da Informação,Campinas, v.5, n. 2, p. 25-52, jan/jun. 2008- ISSN: 1678-765X. 
A inclusão digital ocorre no contexto da Sociedade da Informação que inclui todas as pessoas e o Ministério da Ciência e Tecnologia especifica:

Participação nas ações desenvolvidas pelo Programa Sociedade da Informação - SOCINFO, visando o alcance de sua missão que é o de articular e coordenar o desenvolvimento e a utilização de produtos e serviços avançados de computação, comunicação e conteúdos e suas aplicações, visando a universalização do acesso e a inclusão de todos os brasileiros na sociedade da informação. (http://www.mct.gov.br/index.php/content/view/5258.html)

O Ministério da Ciência e Tecnologia coloca a inclusão digital inserida na inclusão social, ou seja, a inclusão social exige a inclusão digital e, para tanto, vem desenvolvendo esforços para que essa última torne-se realidade. A Figura 1, criada a partir dos dados da Sociedade da Informação, mostra graficamente o processo da Inclusão Digital, que conduz à Inclusão Social.

Figura 1 - O Ciclo da Sociedade da Informação

(baseada em Takahashi, Tadao (Org.). Sociedade da Informação no Brasil - livro verde. 2000)

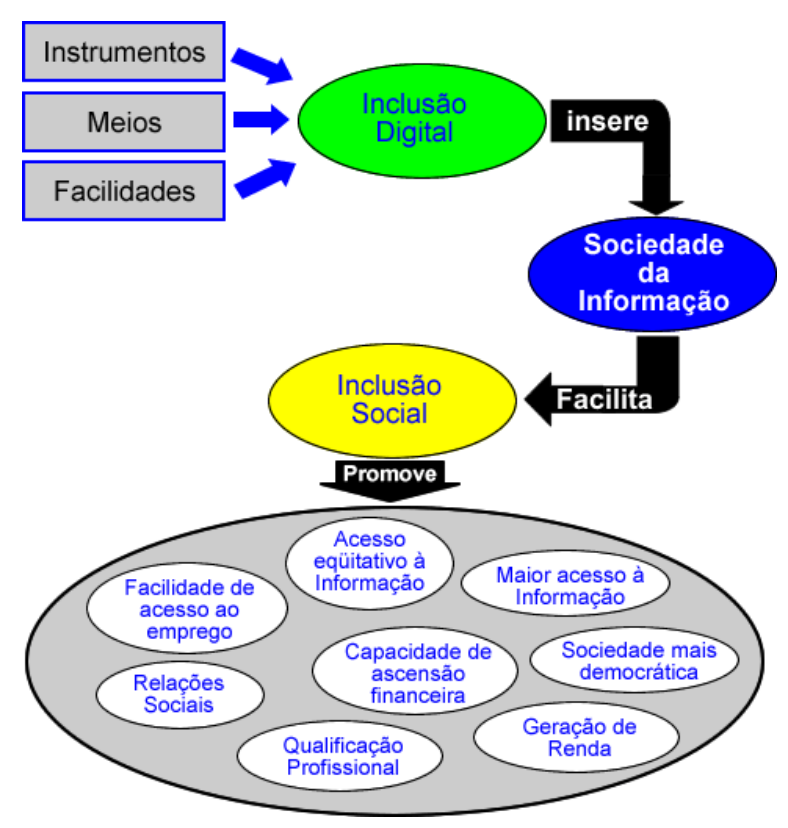

Pela Figura 1 notamos que, para a inclusão Digital, há necessidade da oferta de instrumentos (computadores e “softwares”), meios (acesso à Internet e à redes) e facilidades (capacitação, treinamento e interação). A inclusão digital é uma necessidade para a inclusão social e é esta, em última instância, que irá promover o cidadão através da: facilidade de acesso a emprego, relações sociais, maior acesso à informação, qualificação profissional etc.

O governo brasileiro, e várias Organizações Não-Governamentais - ONG’s, estão trabalhando para que ocorra a inclusão digital da parcela da população brasileira que 
ainda não tem acesso aos computadores e à Internet. Assim são muitas as ações desenvolvidas.

O Ministério do Planejamento, Orçamento e Gestão criou, no ano de 2000, o Governo Eletrônico com a seguinte finalidade ${ }^{2}$ :

- Universalização de serviços;

- Governo ao alcance de todos; e

- Infra-estrutura avançada.

Nesse projeto, no capítulo sobre a inclusão digital, lê-se:
A Inclusão digital deve ser tratada como um elemento constituinte da política de governo eletrônico, para que esta possa configurar-se como política universal. Esta visão funda-se no entendimento da inclusão digital como direito de cidadania e, portanto, objeto de políticas públicas para sua promoção.
a) Construir infra-estrutura de inclusão digital voltada para uso público e comunitário:
A infra-estrutura de acesso não pode ser apenas estatal, mas deve promover a participação dos cidadãos e das organizações da sociedade civil em sua gestão, utilizando referencialmente o modelo de telecentros comunitários utilizando software livre.
(http://www.governoeletronico.gov.br/governoeletronico/publicacao/down_ane xo.wsp?tmp.arquivo=E15_1872diretrizes_inclusao_digital_gov.pdf).

O governo entende a importância do "software" livre para a sociedade, tanto que instituiu um site para tratar do assunto ${ }^{3}$. No artigo 'Inclusão Digital, Software Livre e Globalização Contra-Hegemônica’, é “discutida a questão do software livre e suas implicações econômicas, sociais, políticas e ideológicas” (Silveira ${ }^{4}$ ), como política de combate à exclusão digital. Tal artigo também conclui que o ideal para a inclusão digital é o uso do "software" livre.

O Ministério da Fazenda, por meio do programa Projeto Cidadão Conectado Computador para Todos também especifica o "software” livre:

O Projeto Cidadão Conectado - Computador para Todos... tem como objetivo principal possibilitar a população que não tem acesso ao computador possa adquirir um equipamento de qualidade, com sistema operacional e aplicativos em software livre, que atendam ao máximo às demandas de usuários, além de permitir acesso à Internet.

(http://www.computadorparatodos.gov.br/projeto/index_html)

\footnotetext{
${ }^{2}$ http://www.governoeletronico.gov.br/governoeletronico/publicacao/noticia.wsp?tmp.noticia=90\&tmp.area=18\&wi.redi rect=PPJXRX0SM7

${ }^{3} \mathrm{http}: / /$ www.softwarelivre.gov.br/

${ }^{4}$ http://www.softwarelivre.gov.br/softwarelivre/artigos/artigo_02
}

(c) Revista Digital de Biblioteconomia e Ciência da Informação,Campinas, v.5, n. 2, p. 25-52, jan/jun. 2008- ISSN: 1678-765X. 
Por essas duas recomendações, percebemos a preocupação do governo, partindo do pressuposto de que a máquina e o "software” livre resolvem o problema da inclusão digital, porém, Carvalho (2003, p. 78) observa:

Conseguir a inclusão digital não é um objetivo fácil de ser alcançado. Não basta o reconhecimento e o empenho (governamental, social, técnico e econômico) para encontrar soluções que viabilizem a aquisição de equipamentos e serviços à população. Com determinação política e recursos financeiros é possível disponibilizar equipamentos e serviços à população em curto espaço de tempo, porém, tais facilidades são inúteis se a população não puder fazer uso delas, por falta de treinamento, habilidade ou incapacidade física.

Conforme a Fundação para o Software Livre, a idéia fundamental é a busca de uma alternativa aos “softwares” pagos, conforme o site do projeto GNU, que foi iniciado por Richard Stallman, em 1984, com o objetivo de criar um sistema operacional totalmente livre, que qualquer pessoa tenha o direito de usar e distribuir, sem ter que pagar licenças de uso. O Projeto foi iniciado para desenvolver um sistema operacional completo, compatível com o UNIX, que fosse "software” livre:

o sistema GNU (GNU é um acrônimo recursivo para "GNU Não é UNIX” e é pronunciado como "guh-noo."). Variantes do sistema operacional GNU, que incluem o kernel Linux, são hoje amplamente utilizadas; embora estes sistemas sejam freqüentemente chamados de "Linux", eles seriam mais corretamente chamados de sistemas GNU/Linux. (http://www.gnu.org/home.pt.html).

Todos os computadores necessitam de um "software" especial, chamado Sistema Operacional, para funcionar. O sistema operacional de “software” livre é o "Linux”, que pode ser baixado da Internet ou comprado por uma pequena taxa, até em bancas de revistas. As instruções de construção do "software” estão disponíveis junto do mesmo, ou em sites da Internet, de tal modo que pode ser modificado e adaptado para necessidades particulares.

O Linux é um exemplo de software de código fonte aberto que permite a todos os usuários de computadores acesso livre a seu código de programa... Softwares de código fonte aberto como o Linux não pertencem a nenhuma empresa ou indivíduo. (Laudon e Laudon, 2004, p. 201)

De acordo com a fundação, do "software" livre, destacamos algumas de suas características: Software livre "se refere à liberdade dos usuários executarem, copiarem, distribuírem, estudarem, modificarem e aperfeiçoarem o software” $\left({ }^{5}\right)$.

Outras das características dos “softwares” é a interface de comunicação e interação com o usuário. Os programas para uso comum (utilitários), como uma planilha de cálculo, um

\footnotetext{
${ }^{5}$ http://www.gnu.org/philosophy/free-sw.pt.html 
processador de texto, ou um navegador de Internet ("browse”), dependem totalmente do "software" de sistema operacional, assim, o comportamento dos diversos programas utilitários deve ser compatível com o sistema operacional e a ele devem obedecer. Se a interação com o usuário, promovida pelo sistema operacional, não for amigável (fácil de usar e interativo), os diversos utilitários também não o serão.

Embora a Microsoft não seja a inventora da interface gráfica, foi ela quem a popularizou e a tornou simples com o "Windows”, “cujo arranjo de ícones provê acesso imediato a tarefas comuns” (Laudon e Laudon, 2004, p. 199), fazendo com que sua interface gráfica se tornasse um padrão, provocando, com isso, que grandes produtores de "softwares" construíssem suas interfaces semelhantes às do "Windows".

Para a inclusão digital, faz-se necessária a disseminação dos computadores, mais precisamente as máquinas classificadas como PC - Computador Pessoal, que já são encontradas em larga escala nas organizações em geral (comércio, indústria e serviços) e nas escolas, principalmente as particulares. Para tanto, o governo por meio do programa Projeto Cidadão Conectado - Computador para Todos ${ }^{6}$, apresenta as configurações mínimas para a máquina, convida empresas fabricantes de computadores a participarem do projeto e especifica uma linha especial de financiamento para o consumidor através do FAT - Fundo de Amparo ao Trabalhador, como lê-se em seu "site":

a) Capacidade instalada de conexão à Internet

b) configurado com no mínimo, 26 programas baseados em software livre com as funcionalidades e requisitos definidos no Projeto

c) todo o modelo de Computador para Todos, a ser financiado por recursos do FAT, deverá ter projeto aprovado no Ministério da Ciência e Tecnologia (MCT) e Ministério do Desenvolvimento da Indústria e Comércio (MDIC) ${ }^{7}{ }^{7}$ ).

Outra alternativa estudada pelo governo brasileiro é o “Notebook” de cem dólares, projeto do diretor e co-fundador do Laboratório de Mídia do MIT (Massachusetts Institute of Technology), dos Estados Unidos, Nicholas Negroponte e presidente da ONG “Um computador portátil por criança”, cujo objetivo é possibilitar que todas as crianças tenham acesso à informática e à Internet. O Projeto Cidadão Conectado - Computador para Todos, apresenta em seu "site":

O Governo espera receber a partir de novembro próximo os primeiros protótipos para testes e avaliação do notebook de US\$ 100 para uso em educação... Os protótipos serão produzidos pela organização nãogovernamental One Laptop Per Child (Olpc - Um Computador Portátil por

\footnotetext{
${ }^{6}$ http://www.computadorparatodos.gov.br/participacao/index_html

${ }^{7}$ Ministério do Desenvolvimento, Indústria e Comércio

(c) Revista Digital de Biblioteconomia e Ciência da Informação,Campinas, v.5, n. 2, p. 25-52, jan/jun. 2008- ISSN: 1678-765X.
} 
Criança), ligada ao Massachusetts Institute of Technology (MIT), dos Estados Unidos.

... os aparelhos serão avaliados pelo projeto Um Computador por Aluno

(UCA), uma ação interministerial que envolve os ministérios da Educação

(MEC) e da Ciência e Tecnologia (MCT), juntamente com outros

pesquisadores de institutos brasileiros e que pretende distribuir um computador para cada estudante do sistema de ensino público.

(http://www.computadorparatodos.gov.br/noticias/20060825_01).

Tanto os computadores financiados pelo FAT, como o “Notebook” de 100 dólares, serão entregues ao consumidor final com “softwares” livres instalados.

A compra do computador e dos “softwares” é apenas uma parcela do custo total da implantação de um sistema computadorizado. O TCO - Custo Total de Propriedade, além do "software" e da máquina, envolve manutenção, atualização, suporte técnico e treinamento. "Considerando todos os componentes, o TCO para um PC pode atingir até três vezes o preço original de compra do equipamento” (Laudon e Laudon, 2004, p. 214) e conforme a FUNDAP - Fundação do Desenvolvimento Administrativo do Estado de São Paulo publicou na sua revista:

A adoção do software livre não traz, contudo, apenas vantagens. Apesar dos custos menores do que aqueles impostos pelos softwares proprietários, os softwares livres carregam custos embutidos: é preciso treinar funcionários para usar os novos programas e - para aproveitar os maiores benefícios dessa modalidade de software - manter uma equipe de programadores que adapte, desenvolva e atualize os programas (Fundap, 2005)

Então, os custos não se limitam somente aos “softwares”, mas também ao treinamento, customização (adaptação do software às necessidades do usuário), suporte e manutenção. O treinamento envolve custos para dar treinamento a especialistas e usuários finais dos sistemas de informação (Laudon e Laudon, 2004, p. 215), necessitando, portanto, do treinador (professor de Informática).

A maioria das organizações ainda trabalha com o sistema operacional "Windows” e não o “Linux”, portanto, o usuário, ao ingressar no mercado digital, deverá ter familiaridade com essa interface. Por outro lado, a facilidade de se encontrar profissionais para suporte e treinamento em "softwares" baseados no "Windows" é muito maior do que os especialistas em “Linux”.

A proposta do governo para a inclusão digital é investir primordialmente no computador de baixo custo e no "software" livre, sendo que entendemos como também muito 
importante a capacitação (treinamento), não só no funcionamento da máquina, mas muito mais na interação entre o ser humano e o computador.

Os "softwares" livres, todos funcionando no sistema operacional "Linux", apresentam uma interface peculiar e que é desenvolvida por programadores do mundo todo, tendo como base o paradigma do "software” livre, não existindo, portanto, uma padronização na interface e, muito menos, pessoas de outras áreas como: psicologia cognitiva, “design”, comunicação, educação, publicidade, jornalismo, ou outras afins, que poderiam colaborar na interação entre o ser humano e os computadores. Quanto mais distante essa interação, maior a necessidade de capacitação.

Uma das formas para diminuir os custos necessários à capacitação é utilizar interfaces de fácil interação, preocupação da IHC - Interação Humano-Computador. Na Figura 2, criada a partir das leituras de Carvalho (1994 e 2003), mostramos graficamente a diferença entre o programa do governo brasileiro e uma proposta que chamamos de Programa Útil. Para o programa de inclusão digital do governo, basta oferecer computador barato e "software” livre. Na Figura 2 apresentamos a proposta programa útil, onde é acrescentada a capacitação, que demanda altos investimentos. A maneira de diminuir os investimentos em capacitação (treinamento do usuário) é a construção de uma interface de comunicação com o ser humano, mais interativa, conforme discutido no item 4 a seguir. 
Figura 2 - Programa de Inclusão Digital

(baseada em Carvalho 1994 e 2003)

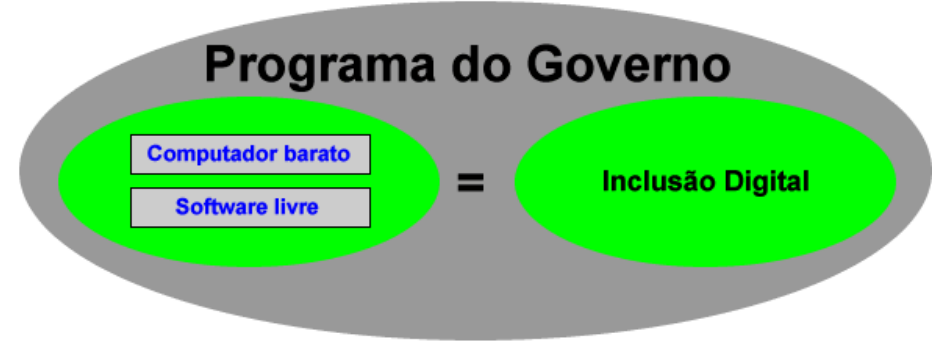

\section{Programa Necessário}

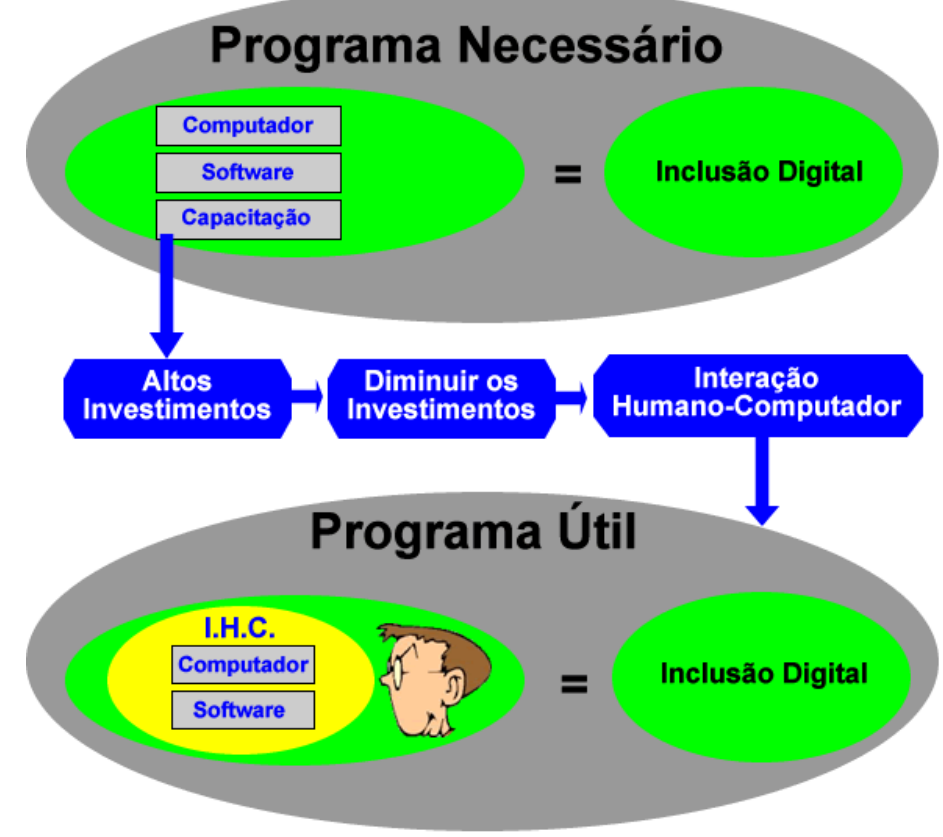

\section{4 - Interação Humano-Computador}

Com o crescente uso e disseminação dos computadores, inclusive em função da diminuição de seus preços, e a popularização da Internet, cada vez mais informações estão sendo disponibilizadas por meio digital, conforme observa Carvalho (2003, p.76):

As informações geradas atualmente estão, cada vez mais, sendo armazenadas no formato digital. As vantagens dessa forma de armazenamento de informação são muitas, destacando-se, entre elas, a flexibilidade oferecida para a sua recuperação e a possibilidade de armazenamento e veiculação em diferentes tipos de mídia.

Assim, surge a necessidade de melhorar a interação entre a máquina e o ser humano. Não que isto seja possível de uma maneira universal, mas ao menos procurando atender a um determinado grupo de usuários. O simples aspecto da leitura já se torna diferente quando usamos o computador, como Nielsen (2000, p. 4) escreve ainda no prefácio de seu livro: 
Os leitores e escritores devem ajustar-se a espaços de informação não-lineares, ou seja, os escritores devem escrever utilizando hipertexto e os leitores, ler sem a segurança mental proveniente de precisar apenas virar a página. Nada, a não ser o tempo e muita experiência e exposição a hipertextos bem feitos, fará essa mudança acontecer.

Segundo Lévy (1996, p.39), o hipertexto ${ }^{8}$, armazenado em um meio físico qualquer, tem um potencial de informação que será realizado quando da interação com um usuário, interação esta que é muito diferente daquela que esse usuário mantém com o livro, e “a tela apresenta-se então como uma pequena janela a partir da qual o leitor explora uma reserva potencial.”

Um aprendizado, portanto, é necessário tanto da parte dos que montam o texto, que não necessariamente são os próprios escritores, e o leitor. Quando quem monta o texto não é o próprio autor, mas um técnico formado em uma das áreas da Informática, acrescentamos mais variáveis à construção do texto, sendo a principal o modelo mental. Ainda não existe, por parte da maioria dos desenvolvedores de soluções digitais, a preocupação com a interação entre o ser humano e a máquina, conforme escreve Carvalho (2003, p. 77):

Em época mais recente, uma nova abordagem sobre o problema apresentado foi destacada, tornando-se um tema de pesquisa na área da computação em crescente desenvolvimento, denominada Interação Humano-Computador (IHC), que aos poucos vem sendo absorvido pelos desenvolvedores de tecnologia digital. A Interação Humano-Computador tem característica multidisciplinar e seu objetivo é tornar máquinas sofisticadas mais acessíveis, no que se refere à interação, aos seus usuários potenciais. Essa abordagem não é exclusiva da área da computação, mas é também compartilhada pela área da Ciência da Informação.

Assim, a necessidade de um novo campo de estudo surge com o termo Interação HumanoComputador - IHC, em meados dos anos 1980, com a seguinte definição: "IHC é a disciplina preocupada com o design, avaliação e implementação de sistemas computacionais interativos para uso humano e com o estudo dos principais fenômenos ao redor deles.” (Rocha e Baranauskas, 2003, p.14).

Em resumo, interação é o processo de comunicação entre pessoas e sistemas interativos, no qual um “fala” e o outro “ouve”, interpreta e realiza uma ação que pode ser uma resposta imediata ou operações complexas que alteram o estado do mundo.

As interfaces são os meios pelos quais há a interação, portanto, são um meio de comunicação entre algum dispositivo e o ser humano (usuário).

\footnotetext{
${ }^{8}$ Hipertexto: Texto em forma eletrônica que foi indexado e conectado (hiperlinks) por “software” em uma série de maneiras de modo a poder ser consultado de forma aleatória e interativa por um usuário. (O’BRIEN, 2001, p. G-14)
}

(c) Revista Digital de Biblioteconomia e Ciência da Informação,Campinas, v.5, n. 2, p. 25-52, jan/jun. 2008- ISSN: 1678-765X. 
Para o usuário, a interação se dá com e através da máquina (dispositivo físico) e a interface, na grande maioria das vezes, é confundida com o "software”, quando, na realidade, é todo o Sistema de Informações, conforme resume Carvalho (1994, p.11):

Resumindo, interface homem-computador se refere ao conjunto (meio e métodos de comunicação, modelos mentais, software e hardware), que serve como intermediário para efetuar a troca de informações entre o ser humano e o computador e pode ser referenciado de várias maneiras na literatura técnica especializada.

A Figura. 3, criada a partir de Carvalho e Rocha e Baranauskas, mostra graficamente a interface, que é uma ferramenta que pode ser considerada como a extensão dos órgãos do homem, portanto, psicologicamente, uma boa ferramenta é aquela que está associada ao aprimoramento desses órgãos ou que represente uma extensão da sensorialidade humana (Novo, 2004, p. 87).

Figura 3 - Interface de Sistema

(baseada em Carvalho 2003 e Rocha e Baranauskas 2003)

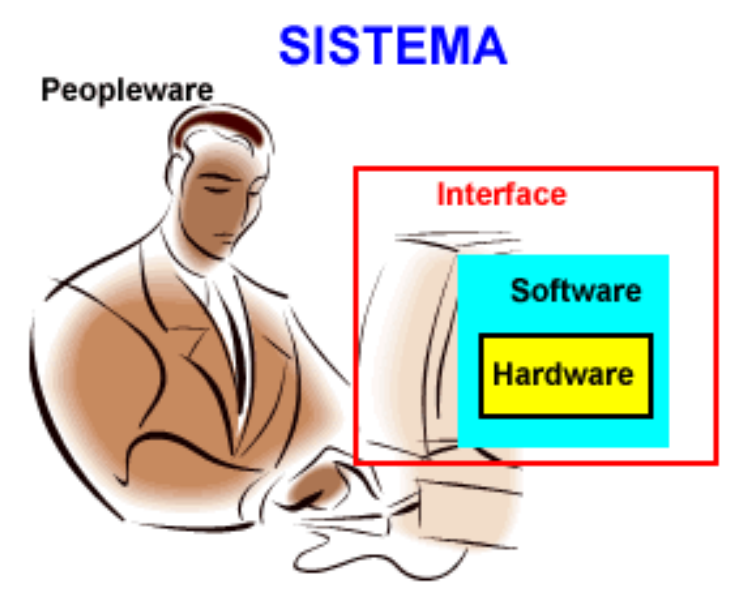

Os objetivos da disciplina IHC são de orientar os desenvolvedores a produzirem sistemas que sejam simultaneamente, seguros e funcionais, entendendo-se sistemas não apenas o “software”, mas todo o contexto, incluindo: “software”, "hardware”, as pessoas, ambiente físico, as tecnologias computacionais, bem como o "design” das interfaces, que é a concepção e exposição dos traços gerais da interface para facilitar aos usuários o desempenho de tarefas. O “design” deve estar centrado no usuário e não na máquina. Rocha e Baranauskas (2003, p.105) escrevem:

O processo de design em IHC tem sido naturalmente centrado no usuário e têm incorporado questões relativas a modelos cognitivos do processamento humano ...Existe uma grande influência de métodos da engenharia, em particular da Engenharia de Softwares em IHC, através do design e desenvolvimento de software. Por outro lado, teorias de design originais de contextos diversos, em particular o design industrial, arquitetônico e gráfico também têm influenciado a maneira como design de interfaces tem sido feito recentemente.

(C) Revista Digital de Biblioteconomia e Ciência da Informação,Campinas, v.5, n. 2, p. 25-52, jan/jun. 2008- ISSN: 1678-765X. 
Para o programa de inclusão digital do governo brasileiro, entendemos que deveria ser realizada uma pesquisa de campo com os sujeitos alvos do programa, para verificar se a interação, em função do “design” das interfaces dos "softwares” livres colocados à disposição, atinge a compreensão desse público.

A leitura na “web”, um dos objetivos da inclusão digital, é diferente da leitura em textos impressos, sendo afetada por vários fatores, segundo Almeida (2003, p.90), como a disposição do texto na página, o tipo e tamanho de letra utilizado, o tipo do monitor do computador do usuário, a ergonomia do mobiliário e até a iluminação do ambiente, ou seja, essa interação é diferente daquela verificada com o livro. Nielsen, (2000, p. 12) aborda, para o "design” na "web”, o emprego da engenharia da usabilidade, que consiste em pesquisar diretamente junto aos usuários qual o melhor “design” entre, por exemplo, duas opções, ou questionar o usuário sobre as dificuldades encontradas para navegar em determinado site.

A Engenharia da Usabilidade, proposta desde a década de 1980, propõe o uso de métodos empíricos (consultas realizadas diretamente com usuários dos sistemas) ao “design” e, sendo assim definida: "Engenharia de Usabilidade é o termo que se usa para definir o processo de design de sistemas computacionais que objetivam a facilidade de aprendizado, de uso, e que sejam agradáveis para as pessoas” (Rocha e Baranauskas, 2003, p.120).

A usabilidade é um dos critérios de aceitação de um sistema. Embora a satisfação (agradabilidade) do usuário seja subjetiva, se a consulta (pesquisa) ocorrer com muitos usuários, a média das respostas passa a ser uma medida objetiva (Rocha e Baranauskas, 2003 p.32).

Para o correto desenvolvimento do “design” que contemple a usabilidade, é necessário o entendimento dos modelos mentais e os aspectos de aprendizagem e retenção das informações, conforme Carvalho (1994, p. 27):

Ao se falar de interfaces homem-computador está se referindo a interfaces que devem se adaptar não apenas aos aspectos físicos do ser humano (como teclados com formatos que permitem uma posição mais cômoda das mãos), e sim, em maior quantidade, aos aspectos mentais do ser humano, ou seja, à interação do intelecto do ser humano, através dos órgão sensitivos, com o software aplicativo, através da interface (entradas e saídas) do computador.

(c) Revista Digital de Biblioteconomia e Ciência da Informação,Campinas, v.5, n. 2, p. 25-52, jan/jun. 2008- ISSN: 1678-765X. 
O consumidor da informação gerada pelos sistemas computacionais é o ser humano, informação essa que deverá contribuir para a formação do seu conhecimento (aprendizado), portanto, a interface com seu “design” devem obedecer aos modelos mentais dos humanos. Pela facilidade com que é possível navegar nos "softwares”, há grandes possibilidades de o usuário perder-se ou esquecer o ponto de partida de sua pesquisa. Assim, é importante a sua memorização ou “designs” inteligentes, que facilitem essa memorização.

O Problema agrava-se quando, no desenvolvimento do sistema, o programador também acumula a função de “designer”, e conforme Carvalho (1994, p. 38):

Muitos sistemas de informação, infelizmente, são desenvolvidos por profissionais que apesar de possuírem um bom conhecimento técnico dos aspectos computacionais (hardware e software) dos sistemas, praticamente desconhecem os aspectos humanos. Para muitos deles o projeto de interfaces amigáveis são considerados de menor importância em seus projetos, quando são considerados. Tais profissionais constroem interfaces sem levar em conta os processos envolvidos no pensamento dos usuários e consideram que os modelos mentais dos sistemas, construídos pelos usuários, são semelhantes aos seus.

A dificuldade de encontrar "links" e objetos ou entender os objetos nas interfaces, que podem ser agravadas pelas diferenças dos Modelos Mentais, ou seja, as dificuldades de interação do ser humano com o computador podem gerar dificuldades na recuperação da Informação.

Entre os vários objetivos da Ciência da Informação, destacamos a disseminação e a recuperação da informação, que acreditamos também seja o foco do governo brasileiro para desenvolver programas de Inclusão Digital, assim, o desafio é construir interfaces que proporcionem uma Interação Humano-Computador que seja de fácil aplicação a todas as camadas da sociedade e em especial aos excluídos digitalmente.

\section{5 - Pesquisa}

Realizamos uma pesquisa exploratória aplicada, utilizando Levantamento (questionamento direto das pessoas, cujo comportamento se deseja conhecer) e mediante análise quantitativa procuramos obter as respostas às dúvidas levantadas na introdução. Como optamos pela amostragem não-probabilística e método Levantamento, escolhemos sujeitos, em princípio, com maiores necessidades de inclusão digital:

(c) Revista Digital de Biblioteconomia e Ciência da Informação,Campinas, v.5, n. 2, p. 25-52, jan/jun. 2008- ISSN: 1678-765X. 
- Alunos do Ensino Fundamental (da quinta à oitava série) de escolas onde estejam presentes computadores com "softwares" livres e alunos de escola com “softwares” proprietários (comprados), especificamente o “Windows”.

Para a realização da pesquisa, foram utilizados questionários com perguntas que visaram avaliar a usabilidade, a dificuldade ou facilidade em interagir com os computadores, pelos diversos públicos, preenchidos por ocasião de entrevistas com os diversos tipos de usuários: Gestores, técnicos, docentes e alunos.

As informações foram obtidas em escolas nas cidades de Campinas e Sorocaba, ambas no estado de São Paulo, no mês de outubro de 2006:

1. Escola A: escola Municipal, com um laboratório de informática utilizando o Sistema Operacional "Linux” e o pacote “OpenOffice"”, ambos softwares livres; não tem acesso à Internet;

2. Escola B: Escola Particular, com um laboratório de informática utilizando Sistema Operacional “Windows 98” e pacote “MS Office 97"10”, ambos da Microsoft;

3. Escolas C e D: Escola Estadual, com um laboratório de informática utilizando o Sistema "Dual Boot”"11 com os Sistemas Operacionais "Linux" e "Windows”; não tem acesso à Internet.

O levantamento de dados ocorreu em contato direto com os sujeitos alvos da pesquisa, apresentando um termo de consentimento livre e esclarecido, explicando o objetivo da mesma, dos questionários, sanando dúvidas e acompanhando o processo do início à entrega dos questionários, e foram entrevistados: 3 Gestores, 2 técnicos, 8 docentes e 25 alunos.

\footnotetext{
9 “O OpenOffice.org 1.0 foi o primeiro produto a trazer os benefícios do software de código aberto a uma grande massa de usuários, distribuindo de forma completamente gratuita ferramentas de produtividade absolutamente essenciais no dia-a-dia. Traduzido em mais de 30 idiomas, disponível nas principais plataformas (Microsoft Windows, Mac OS X X11, GNU/Linux, Solaris), o OpenOffice.org 1.x está em uso por dezenas de milhões de usuários satisfeitos ao redor do mundo.” (http://www.broffice.org/produto). As principais ferramentas de produtividade são: processador de textos, planilha de cálculo e apresentação multimídia, pretendendo serem compatíveis com Word, Excel e PowerPoint da Microsoft.

10 "O Microsoft Office Small Business Edition 2003 inclui softwares conhecidos e fáceis de usar para ajudá-lo a vencer os desafios de administrar um negócio. Você e seus funcionários poderão gerenciar clientes e oportunidades de vendas com maior eficácia, criar na própria empresa incríveis materiais de vendas e marketing, processar e-mails e compartilhar informações com eficiência. O Microsoft Office 2003 inclui cinco programas em um: Word 2003, Excel 2003, PowerPoint ${ }^{\circledR}$ 2003, Outlook 2003 com Business Contact Manager e Publisher 2003.” (http://www.microsoft.com/brasil/pequenasempresas/products/officesbe/default.mspx).

11 “Dual Boot” possibilidade de o computador iniciar com um de dois Sistemas Operacionais instalados no disco rígido.

(C) Revista Digital de Biblioteconomia e Ciência da Informação,Campinas, v.5, n. 2, p. 25-52, jan/jun. 2008- ISSN: 1678-765X. 
Como gestor, entrevistamos os seguintes sujeitos:

Escola A: Diretora; Escola B: Orientadora Pedagógica; Escola C: Diretora; Escola D: a Diretora optou por não responder ao questionário.

Uma observação importante é o fato de os gestores ainda não estarem totalmente informados sobre a questão informática ou sobre qual a real abrangência da recuperação da informação utilizando esse meio. A escola A, não mantém técnico e nas necessidades de atendimento, devem solicitar à Secretaria de Educação Municipal que aciona o IMA Informática dos Municípios Associados ${ }^{12}$. A escola B mantém uma técnica formada em Sistemas de Informação e, durante a entrevista e preenchimento do questionário, reclamou da demora das atualizações dos "softwares”, pois a escola ainda funciona com o “Windows” 98 e o “MS Office” 97, versões já desatualizadas.

As escolas C e D devem solicitar à SEE (Secretaria de Educação Estadual) as eventuais necessidades técnicas. Entrevistamos uma das técnicas na SEE - Regional Sorocaba (que não é formada na área, e sim uma professora que foi remanejada da sala de aula), que, além de responder ao questionário, nos informou que o Estado de São Paulo não é radical quanto ao uso dos “softwares” livres. Os programas 'Trilha das Letras' e 'Números em Ação' (utilizados como reforço às aulas normais), foram desenvolvidos em parceria com uma produtora de "softwares" para trabalhar no sistema operacional "Windows". Informou-nos que só teve um treinamento em "Linux" e foi utilizada a distribuição Debian $^{13}$, sendo que as máquinas “dual boot” enviadas às escolas, foram entregues com a distribuição ${ }^{14}$ Conectiva. Para os "softwares” livres, conforme na Licença Pública GNU lemos, na introdução:

As licenças de muitos softwares são desenvolvidas para cercear a liberdade de uso, compartilhamento e mudanças. A GNU Licença Pública Geral ao contrário, pretende garantir a liberdade de compartilhar e alterar softwares de livre distribuição - tornando-os de livre distribuição também para quaisquer usuários (http://lie-br.conectiva.com.br/licenca_gnu.html).

\footnotetext{
${ }^{12}$ A Informática de Municípios Associados S/A (IMA) é uma empresa de economia mista especializada em Tecnologia da Informação e Comunicação (TIC) e Serviços Gráficos, também responsável pela Imprensa Oficial do Município de Campinas. Ela oferece soluções que auxiliam a administração pública ou privada na busca de melhores resultados de gestão (http://www.ima.sp.gov.br/index.php?go_to_page=pg_institucional)
}

${ }^{13}$ O Projeto Debian é uma associação de indivíduos que têm como causa comum criar um sistema operacional livre. O sistema operacional que criamos é chamado Debian GNU/Linux, ou simplesmente Debian. Os sistemas Debian atualmente usam o kernel Linux. Fonte: http://www.debian.org/intro/about

${ }^{14}$ Pelo fato de o Linux ser um software de livre distribuição, muitas pessoas e até mesmo empresas se empenham em organizar o kernel e mais uma série de aplicativos e manuais para que o sistema fique cada vez mais amigável. A esse conjunto de aplicativos mais o kernel dá-se o nome de distribuição Linux. Algumas distribuições Linux são maiores que outras, dependendo da quantidade de aplicativos e a finalidade a que se propõem. Existem desde distribuições que cabem num disquete de 1.44Mb até distribuições que ocupam vários CDs.

Fonte: http://www.conectiva.com/doc/livros/online/10.0/usuario/pt_BR/ch01s03.html 
Assim, as distribuições têm diferenças entre si, dependendo do critério que cada uma usa ou que quesito acredita ser mais importante, o que dificulta a usabilidade do software, uma vez que não há um padrão estabelecido. Ao referir-se ao "Windows" basta conhecer a versão (“Windows” 95; “Windows” 98; “Windows XP”), já para o “Linux” há a necessidade de conhecer-se a versão de cada distribuidora (“Conectiva Mandriva One”; “Conectiva Mandriva Linux 2007”15; “Debian 3.1”; “SUSE Linux Professional”; “SUSE Linux Enterprise 10”; “Red Hat Enterprise Linux” etc.).

As escolas C e D, em função da falta de treinamento, estão usando apenas o Sistema operacional "Windows". Outra informação que a técnica apresentou foi a de que, o Estado ainda não resolveu o problema de acesso à Internet, assim, as escolas estaduais ainda não podem oferecer acesso à Rede Mundial para seus alunos.

Os docentes foram os sujeitos que mais informações apresentaram. No levantamento da escola A, foram levantados os seguintes fatos:

- "Fica difícil usar os softwares que o departamento de informática da Secretaria de Educação, através da IMA - Informática dos Municípios Associados, disponibiliza, uma vez que fora da escola o que nós encontramos é o "Windows” e o "Office”

- “Não temos treinamento”

- “Quando quero colocar algum texto para os alunos trabalharem, tenho que instalar de máquina em máquina, pois não sabemos usar a rede do "Linux”

- “Não é possível instalar nenhum programa educativo / pedagógico”

- "Não temos programas disponíveis para trabalhar nossas disciplinas, como por exemplo, Enciclopédias, Corpo Humano, Geografia, etc.”

- “Não temos acesso à Internet”.

No levantamento com os docentes da escola B não sugiram comentários adicionais aos questionários.

No levantamento da escola C, foram levantados os seguintes fatos:

\footnotetext{
${ }^{15}$ A Mandriva Conectiva é a operação brasileira da Mandriva, desenvolvedora e distribuidora do sistema operacional Mandriva Linux. A Mandriva é o resultado da fusão ocorrida em fevereiro de 2005 entre a Mandrakesoft, uma das principais distribuições Linux da Europa, com atuação mundial em mais de 120 países, a Conectiva, pioneira na distribuição Linux e código aberto em português, espanhol e inglês para toda a América Latina, a Edge IT na França e a Lycoris nos Estados Unidos. Fonte: http://www.mandriva.com/pt_br/brazil/mandriva_br/empresa 
- "Sei que as máquinas têm "Windows" e "Linux”, porém ao ligar nós escolhemos a opção "Windows"

- “Trabalho com um "Software” disponibilizado pela Secretaria de Educação do Estado de São Paulo, chamado Trilha das Letras para auxílio aos alunos com dificuldades em Língua Portuguesa, e esse "software” é para “Windows”

- “O treinamento que recebemos é somente pedagógico e em como usar esse "software"

- “Sabemos que tem o "Linux" e o “Open Office”, porém não usamos, pois nunca tivemos treinamento"

- “Não temos acesso à Internet”.

No levantamento da escola $\mathrm{D}$, foram levantados os seguintes fatos:

- “As máquinas são “Dual Boot”, porém nós utilizamos somente o "Windows”, eu, por exemplo, trabalho com o programa Números em Ação, enviado pela Secretaria de Educação do Estado de São Paulo, para reforço aos alunos com dificuldades em Matemática”

- “Nós temos reuniões mensais com nossos orientadores, porém é somente sobre como aplicar esses programas ao desenvolvimento dos alunos, não temos treinamento sobre informática”

- "Eu sei que tem o "Open Office” instalado nas máquinas, porém não uso, pois o que vemos na faculdade é o "Windows” e o “Office” (docente aluna de Letras)

- “Não temos acesso à Internet”.

Nas escolas C e D, os professores entrevistados não têm conhecimento sobre a diferença entre os programas aplicativos e o sistema operacional, uma vez que para eles o “software” necessário é o aplicativo fornecido pela SEE.

Para o preenchimento dos questionários aplicados aos alunos, escolhidos aleatoriamente, os mesmos foram colocados em um ambiente separado dos demais alunos, porém no ambiente escolar. Verificamos o interesse dos alunos por programas de interesse geral, e não somente os programas colocados à disposição. Independente do sistema operacional, “softwares” de mensagens são os mais citados, sendo que nominalmente é o programa que funciona no "Windows” (“MSN”) e aceso à Internet. Outros programas mencionados pelos alunos, como “Orkut”, "Flogs”; “Gunbound”, "Skipe” e alguns “Jogos” somente são funcionais caso exista acesso à Internet. 
Na escola A houve a menção do "Windows" e do "Office" como "softwares" conhecidos e/ou desejados.

\section{6 - Conclusões}

Pela pesquisa bibliográfica, constatamos a necessidade de Programas de Inclusão Digital, inclusive como promotores da Inclusão Social ou, pelo menos, como seu facilitador e a necessidade de o Brasil entrar definitivamente na Sociedade da informação. Sociedade esta, que compreendemos como resultado da capacitação dos excluídos digitalmente, para lidar com computadores e "softwares" com o intuito de armazenar, recuperar e disseminar informações, bem como acesso aos computadores.

O Governo Brasileiro mostra preocupação com a inclusão digital, por meio do lançamento de programas voltados para este fim ou, pelo incentivo a programas já existentes. São várias as ações que tentam abarcar o maior número de excluídos digitais. Esses programas são importantes, à medida que propiciam a busca, a pesquisa, a recuperação e a disseminação da informação, tornando, por conseqüência, o conhecimento disponível a uma parcela da população até então excluída dele.

Outro fator importante é o crescimento da Internet, criando espaços virtuais e imensos repositórios de informações e ferramentas para troca dessas informações com rapidez cada vez maior. A disseminação da Internet pelo mundo apresenta a necessidade de saber interagir com essa ferramenta, como premissa básica para a inclusão digital.

Entre os vários programas, projetos e ações para a inclusão digital, destacamos o uso de “software” livre para serem usados nos computadores fornecidos para as escolas públicas ou financiados a juros mais acessíveis para o público objeto desses programas. O “software” livre em questão é o "Linux". Os “softwares” livres ou "softwares” de Licença Pública Geral Gnu, são uma maneira de diminuir os preços para os usuários, frente aos praticados pelos fabricantes de "softwares” proprietários, tornando os sistemas mais acessíveis ao público em geral. Os “softwares” livres, somados aos diversos programas do governo para a colocação dos computadores a preços mais acessíveis aos usuários, inclusive com financiamentos diferenciados, e a distribuição de computadores

(c) Revista Digital de Biblioteconomia e Ciência da Informação,Campinas, v.5, n. 2, p. 25-52, jan/jun. 2008- ISSN: 1678-765X. 
para as escolas públicas podem parecer, em uma análise superficial, medidas solucionadoras para a inclusão digital.

Um fator que o programa do governo brasileiro não considerou foi a interação do usuário com as máquinas, interação essa que se dá através da interface do sistema operacional, sistema que será suporte para todos os outros programas que serão utilizados no computador.

Para a implantação desses programas, além dos computadores e “softwares”, há a necessidade de capacitação dos usuários, principalmente dos docentes das escolas públicas que devem ser os agentes de multiplicação. Para a capacitação dos docentes há a necessidade de contratação de professores de informática ou a contratação de empresas terceirizadas que cuidariam dessa capacitação.

Uma alternativa seria o uso dos “softwares” proprietários, mais especificamente o "Windows" que, por já ter uma base instalada muito grande, inclusive nas escolas particulares onde se formam professores, não exigiria muito treinamento dos docentes ou, pelo menos, demandaria investimentos menores neste sentido. Outra alternativa seria trabalhar o desenvolvimento das interfaces dos “softwares" livres, considerando a Interação Humano-Computador - IHC, que abrange os aspectos psicológicos e cognitivos do ser humano, de forma que o sistema operacional fosse o mais transparente possível.

Um segundo fator a ser considerado é a ausência de acesso à Internet, que impede a pesquisa nas imensas bases de dados e a troca de informações entre os seus usuários.

Pelas pesquisas realizadas junto aos sujeitos, pudemos inferir que:

1. O Governo não tem um programa de capacitação de docentes para o uso dos "softwares" livres;

2. O governo não tem técnicos em número suficiente para dar suporte às escolas públicas;

3. Os docentes não têm familiaridade com o "Linux”, “OpenOffice” ou qualquer outro "software" livre;

4. Os usuários, tanto alunos quanto docentes, têm familiaridade, ou pelo menos alguma, com o "Windows" e o "MS Office";

5. Os alunos e docentes preferem o "Windows" e o "MS Office"; 
6. Os alunos já têm familiaridade com aplicativos ("MSN”, jogos etc.) construídos para o sistema operacional "Windows”, o que torna a interação com qualquer outro programa, construído para esse sistema, mais fácil (modelo mental próximo);

7. Os "softwares" que os estudantes de escolas particulares encontram são o "Windows" e o “MS Office”, e por conseqüência, os docentes, em seu processo de formação, também;

8. O “Linux”, pela própria definição da Licença Pública Geral Gnu, pode ter variações entre as diversas distribuições, o que torna o produto não padronizado;

9. O governo trabalha com licitações públicas, sendo que isso pode provocar a entrega de computadores com distribuições de "Linux" diferentes em cada lote;

10. Os “softwares" livres são largamente utilizados pelas comunidades de técnicos e estudantes dos diversos cursos de computação provocando, na construção da interface, quando construídas por esses técnicos, um modelo mental diferente do modelo mental do usuário não técnico;

11. Existem poucos "softwares" aplicativos, voltados para alunos de Ensino Fundamental, construídos para o sistema operacional "Linux";

12. Para os alunos, principal público alvo da inclusão digital, a interface "Windows” tem maior usabilidade;

13. Para os gestores, a usabilidade, a facilidade de manutenção e suporte e a recuperação da informação são melhores com a interface "Windows";

14. Para os docentes, a usabilidade é muito melhor com a interface "Windows";

15. A falta de acesso à Internet dificulta o processo de inclusão digital e a busca e recuperação de informação.

Na introdução destacamos duas dúvidas, para as quais propomos as seguintes respostas:

1. A alternativa em usar "softwares” livres, cuja interface é desenvolvida para quem já está integrado no mundo digital, resolverá o problema da inclusão digital?

Pelo apresentado, somos levados apensar que não, pois o processo demandará muito treinamento, não só dos docentes mas também de técnicos, e a incerteza de que os sujeitos objetos da pesquisa estarão inclusos, uma vez que a interface e os "softwares" aplicativos que ele encontrará no mercado são diferentes dos encontrados no universo dos "softwares" livres.

2. A falta de um programa de capacitação ou do desenvolvimento de interfaces que promovam a Interação Humano-Computador prejudica a inclusão digital? 
Pelo apresentado, somos levados a pensar que sim, pois a capacitação, tanto de técnicos quanto dos docentes, é necessária. A construção de interfaces para promover uma Interação Humano-Computador, em que o tipo de sistema operacional não interfira, facilitaria a inclusão digital.

Assim, a combinação de computador mais acessível, “software” livre, acesso à Internet e o destaque necessário em IHC tornariam o processo de inclusão digital mais viável.

A pesquisa sugere que o caminho tomado pelo governo, embora útil, não é completo o suficiente para atingir os propósitos desejados.

\section{7 - REFERÊNCIAS}

ACESSIBILIDADE, TECNOLOGIA DA INFORMAÇÃO E INCLUSÃO DIGITAL ATIID. Universidade de São Paulo - Faculdade de Saúde Pública. Inclusão Digital. Disponível em: <http://hygeia.fsp.usp.br/acessibilidade/index.html>. Acesso em: 7 set. 2006.

ALMEIDA, Rubens Queiroz. O leitor-navegador (II). In: SILVA, Ezequiel (Coord.). A leitura nos oceanos da internet. São Paulo: Cortez, 2003.

BARRETO, Aldo A. Transferência da informação para o conhecimento. In: AQUINO, Mirian (Org.). O campo da ciência da informação - gênese, conexões e especificidades. João Pessoa: Editora Universitária/UFPB, 2002.

CARVALHO, José Oscar F. Referenciais para projetistas e usuários de interfaces de computadores destinadas aos deficientes visuais. 1994. Dissertação (Mestrado) Universidade Estadual de Campinas, Campinas, 1994.

CARVALHO, José Oscar F. O papel da interação humano-computador na inclusão digital. In: Revista Transinformação. Programa de Pós-Graduação em Ciência da Informação da Pontifícia Universidade Católica de Campinas, Campinas, v.15, n.3, ed. espec., p. 75-89, set./dez. 2003. (ISSN 0103-3786).

Fundação pelo Software Livre. O sistema operacional GNU. Disponível em: <http://www.gnu.org/home.pt.html>. Acesso em: 8 set. 2006.

FUNDAP - Fundação do Desenvolvimento Administrativo do Estado de São Paulo. Revista Eletrônica. Governos testam possibilidades do software livre. Ano 2, n.5, jul. 2005. Disponível em: <http://www.revista.fundap.sp.gov.br/revista4/paginas/4governoeletronico.htm>. Acesso em: 8 set. 2006.

Governo Eletrônico. Ministério do Planejamento, Orçamento e Gestão. Projeto Computadores para Inclusão. Disponível em: <http://www. governoeletronico.gov. br/governoeletronico/publicacao/noticia.wsp?tmp.noticia=240\&tmp.area= 
12\&wi.redirect=6ROGTO5GN6>. Acesso em: 8 set. 2006.

HOUAISS, Antonio. Dicionário eletrônico Houaiss da língua portuguesa. Versão 1.0. Rio de Janeiro: Objetiva, 2001. CD-ROM.

IMA. Informática de Municípios Associados S/A. Disponível em: $<$ http://www.ima.sp.gov.br/index.php?go_to_page=pg_institucional $>$. Acesso em: 8 out. 2006.

LAUDON, Kenneth C.; LAUDON, Jane P. Sistemas de informação gerenciais. 5. ed. São Paulo: Prentice Hall, 2004.

LE COADIC, Yves-François. A ciência da informação. Brasília: Briquet de Lemos Livros, 1996.

LÉVY, Pierre. O que é o virtual. São Paulo: Editora 34, 1996.

MCT - Ministério da Ciência e Tecnologia. Sobre a inclusão digital. Disponível em: <http://www.mct.gov.br/index.php/content/view/9751.html\#>. Acesso em: 7 set. 2006.

MICROSOFT. Pacote “Office”. Disponível em: http://www.microsoft. com/brasil/ pequenasempresas/products/officesbe/default.mspx . Acesso em: 08 out. de 2006.

Ministério da Fazenda. Projeto Cidadão Conectado - Computador para Todos. Disponível em: <http://www.computadorparatodos.gov.br/>. Acesso em: 8 set. 2006.

NIELSEN, Jakob. Projetando Websites - Designing Web Usability. Rio de Janeiro: Campus, 2000.

NOVO, Lorival de Campos. Considerações acerca da informática na atitude humana: o computador e a Internet como ferramenta do ser humano. In: FARAH, Rosa M. (Org). Psicologia e informática: o ser humano diante das novas tecnologias / NPPI - Núcleo de Pesquisas em Psicologia e Informática. São Paulo: Oficina do Livro Editora, 2004.

OPENOFFICE. Pacote de Aplicativos. Disponível em: $<$ http://www.broffice.org/produto>. Acesso em: 8 out. 2006.

PRATES, Raquel Oliveira; BARBOSA, Simone D. Junqueira. Avaliação de interfaces de usuário - conceitos e métodos. CONGRESSO DA SOCIEDADE BRASILEIRA DE COMPUTAÇÃO, 23., 2003, Campinas. Anais... Campinas, 2003.

ROCHA, Heloisa V.; BARANAUSKAS, Maria Cecília C. Design e avaliação de interfaces humano-computador. Campinas: NIED/UNICAMP, 2003.

SILVEIRA, Sérgio Amadeu. Inclusão digital, software livre e globalização contrahegemônica. Disponível em: <http://www.softwarelivre.gov.br/softwarelivre/ artigos/artigo_02>. Acesso em: 8 set. 2006.

TAKAHASHI, Tadao (Org.). Sociedade da Informação no Brasil - livro verde. Brasília: Ministério da Ciência e Tecnologia, 2000. 


\section{Calixto Silva Neto}

Mestre em Ciência da Informação PUC - Campinas - 2006

Coordenador dos Laboratórios Acadêmicos de Informática do Objetivo e ESAMC Sorocaba, do Auditório ESAMC e Recursos Audiovisuais da ESAMC Sorocaba, da disciplina Tecnologia da Informação da ESAMC, em nível Nacional.

Professor da Graduação nos cursos de Administração de Empresas e de Comunicação. Professor do MBA ESAMC. professor@calixto.com.br

\section{José Oscar Fontanini de Carvalho}

Doutorado em Engenharia Elétrica. Universidade Estadual de Campinas, UNICAMP Professor titular da PUC - Campinas. Pontifícia Universidade Católica de Campinas. oscar@puc-campinas.edu.br

\section{Recebido em: 15/12/2006}

Aceito para publicação em: jun. 2007 